\title{
Modification of self-assembled films with antibacterial properties on stainless steel surfaces
}

\author{
J.-H. Horng ${ }^{1}$, W.-H. Kao ${ }^{2}$, H.-J. Tsai ${ }^{3}$, Y.-H. Chen ${ }^{1}$ \& C.-C. Yu ${ }^{1}$ \\ ${ }^{I}$ Department of Power Mechanical Engineering, \\ National Formosa University, Taiwan \\ ${ }^{2}$ Department of Automation Engineering and Institute of \\ Mechatronoptic Systems, Chienkuo Technology University, Taiwan \\ ${ }^{3}$ Department of Power Mechanical Engineering, \\ Wu Feng University, Taiwan
}

\begin{abstract}
Stainless steel is used widely to produce medical and mechanical equipment and items of daily use. However, if one were to improve the antibacterial and antipollution functionalities of stainless steel, it would increase the range of its applications. In this study, we synthesised self-assembled molecular films of an organic silane (octadecyltrichlorosilane) mixed with an antimicrobial agent on stainless steel substrates. We employed the Taguchi method to optimise the synthesis process factors, which included the soaking temperature, drying temperature, soaking time, concentration of self-assembling agent, and concentration of antimicrobial agent. We found that the largest contact angle of the self-assembled films was $116.0^{\circ}$, and their antibacterial activity value was 5.7; the latter is higher than the standard value for materials used for industrial and biomedical applications.

Keywords: self-assembled film, antibacterial effect, contact angle, hydrophobic property.
\end{abstract}

\section{Introduction}

Single-layered self-assembled films have been shown to be a reliable and stable way of according antipollution characteristics to materials. However, the selfassembly of hybrid films has not been highly successful, as the synthesis process 
is complicated and difficult to control. Numerous studies have been performed on this issue [1-3] to determine the main factors affecting the properties of such hybrid molecular films. These include the type and concentration of the pharmaceutical used, ambient environment (temperature and humidity), choice of the base material, soaking reaction time, and water content of the pharmaceutical solution. In 2008, Thebault et al. [4] proposed the use of antiseptic equipment coated with a film of quaternary ammonium thiol derivatives, which can kill harmful microorganisms, such as Pseudomonas aeruginosa, Staphylococcus aureus, Aspergillus niger, and Candida albicans, effectively. This proved to be a good microbiophagy strategy. In 2009, they [5] used quaternary ammonium thiol derivatives to synthesise a self-assembled film, according the coated surface antibacterial properties. The film effectively restrained the growth of $\mathrm{S}$. aureus. However, the resulting residues posed a problem. Furthermore, the active antibacterial drug continued to affect the surrounding environment. In this study, we used the Taguchi method to study the antibacterial and antifouling functionalities of biocompatible self-assembled films.

\section{Experimental}

In this study, the properties of molecular films self-assembled on stainless steel surfaces by the liquid-phase preparation method were investigated. The stainless steel substrates were placed in deionised water, cleaned by ultrasonication for $1 \mathrm{~min}$, and blow dried with nitrogen. The substrates were then put into a solution of an antibacterial silane and an antifouling agent, to allow a molecular film to form on their surfaces. The silane used was octadecyltrichlorosilane (OTS), which is antibacterial and exhibits biological compatibility. Deionised water was added to the antibacterial stock solution to form solution samples with concentrations of $10 \%, 30 \%, 50 \%$, and $70 \%$ (vol). The substrates were submerged into these solutions to make the molecular film grow on their surfaces. A schematic diagram of the synthesis process is shown in Figure 1.

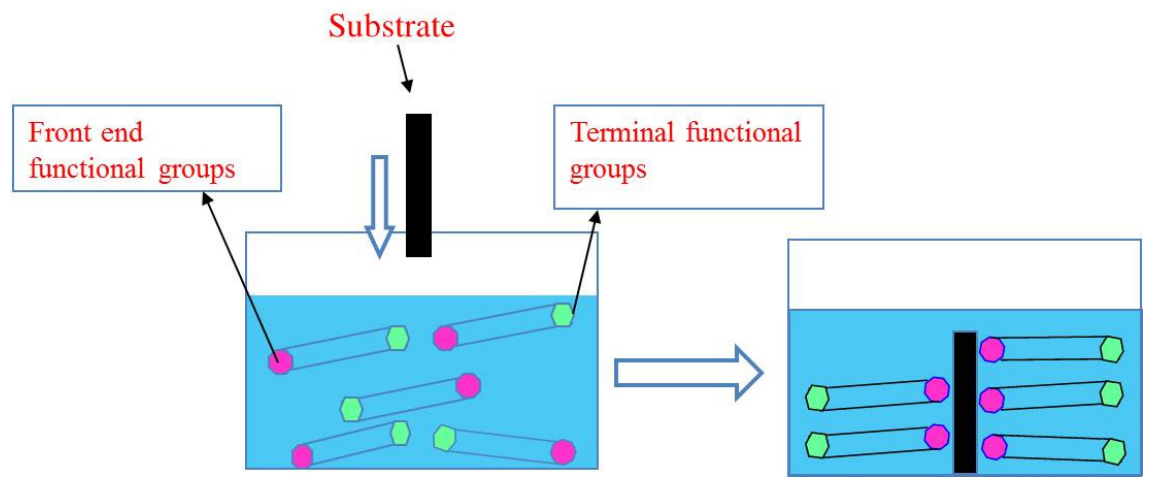

Figure 1: Schematic diagram of the process used for synthesizing the selfassembled molecular films. 
The temperature for the synthesis of the film was set using the temperature control box. After the completion of the film self-assembly process, the substrates were removed from the solution. Using the temperature control box, the soaking temperature was lowered slightly, to dry the substrates for $10 \mathrm{~min}$. Next, the surface contact angles of the substrates were measured. A drop of a liquid was placed on the test surface. An image was taken and analysed to determine the contact angle and thus confirm that a self-assembled film had been synthesised on the surfaces of the stainless steel substrates.

Because a number of factors are involved in the synthesis of hybrid selfassembled films, the Taguchi method was used to optimise the parameters. Table 1 shows the Taguchi orthogonal array for the hybrid self-assembled molecular films synthesised in the present study. The factors include the soaking

Table 1: Taguchi orthogonal array for the hybrid self-assembled molecular films formed on stainless steel substrates.

\begin{tabular}{|c|c|c|c|c|}
\hline $\begin{array}{l}\text { Soaking } \\
\text { temperature } \\
\left({ }^{\circ} \mathrm{C}\right)\end{array}$ & 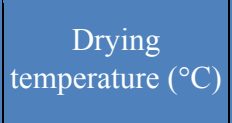 & $\begin{array}{l}\text { Soaking time } \\
\text { (h) }\end{array}$ & $\begin{array}{l}\text { Concentration of } \\
\text { self-assembling } \\
\text { agent }(\mathrm{mM})\end{array}$ & $\begin{array}{l}\text { Concentration } \\
\text { of antimicrobial } \\
\text { agent (\%) }\end{array}$ \\
\hline 50 & 35 & 0.1 & 5 & 10 \\
\hline 50 & 45 & 0.5 & 10 & 30 \\
\hline 50 & 55 & 6 & 15 & 50 \\
\hline 50 & 65 & 12 & 20 & 70 \\
\hline 60 & 35 & 0.5 & 15 & 70 \\
\hline 60 & 45 & 0.1 & 20 & 50 \\
\hline 60 & 55 & 12 & 5 & 30 \\
\hline 60 & 65 & 6 & 10 & 10 \\
\hline 70 & 35 & 6 & 20 & 30 \\
\hline 70 & 45 & 12 & 15 & 10 \\
\hline 70 & 55 & 0.1 & 10 & 70 \\
\hline 70 & 65 & 0.5 & 5 & 50 \\
\hline 80 & 35 & 12 & 10 & 50 \\
\hline 80 & 45 & 6 & 5 & 70 \\
\hline 80 & 55 & 0.5 & 20 & 10 \\
\hline 80 & 65 & 0.1 & 15 & 30 \\
\hline
\end{tabular}


temperature $\left(50^{\circ} \mathrm{C}, 60^{\circ} \mathrm{C}, 70^{\circ} \mathrm{C}\right.$, and $\left.80^{\circ} \mathrm{C}\right)$, drying temperature $\left(35^{\circ} \mathrm{C}, 45^{\circ} \mathrm{C}\right.$, $55^{\circ} \mathrm{C}$, and $\left.65^{\circ} \mathrm{C}\right)$, soaking time $(0.1 \mathrm{~h}, 0.5 \mathrm{~h}, 6 \mathrm{~h}$, and $12 \mathrm{~h})$, concentration of the self-assembling agent ( $5 \mathrm{mM}, 10 \mathrm{mM}, 15 \mathrm{mM}$, and $20 \mathrm{mM})$, and concentration of the antimicrobial agent $(10 \%, 30 \%, 50 \%$, and $70 \%)$.

\section{Results and discussion}

The average surface roughness $\left(S_{\mathrm{a}}\right)$ of the uncoated substrates was $233.2 \mathrm{~nm}$, as shown in Fig. 2(a). The surface topographies of the substrates with selfassembled films of OTS, OTS + anti $10 \%$, and OTS + anti50\%, determined using an atomic force microscopy system, are shown in Figs 2(b), (c) and (d), respectively. The average surface roughness of the substrate covered with the self-assembled OTS film decreased to $182.2 \mathrm{~nm}$, while those of the substrates cover with the hybrid antibacterial self-assembled films of OTS+anti10\% and OTS+anti50\% decreased further, to $87.9 \mathrm{~nm}$ and $95.6 \mathrm{~nm}$, respectively, as shown in Fig. 3. This suggested that hybrid self-assembling agents can decrease the surface roughness of the substrate and alter its surface properties. The concentration of antimicrobial agent has not significant effect on the average surface roughness of surface films.

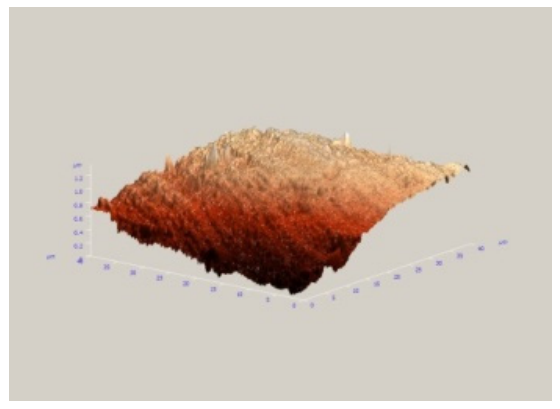

(a)

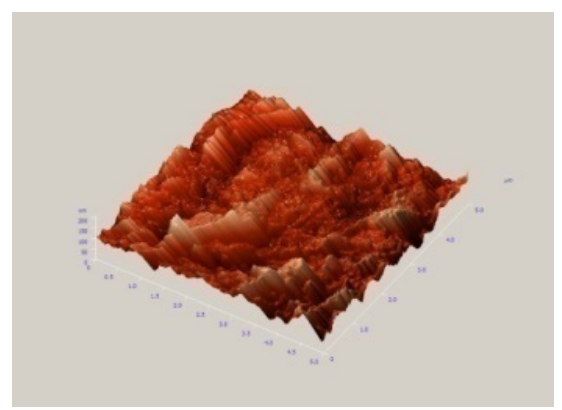

(c)

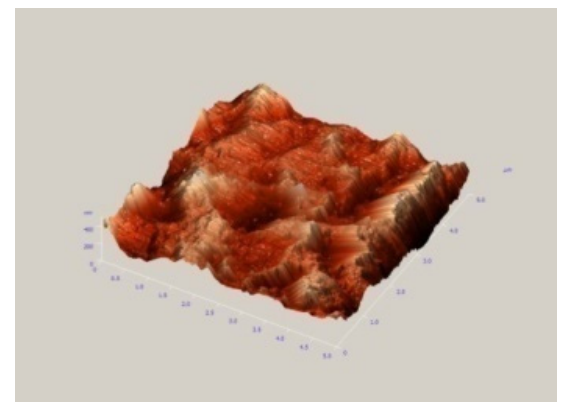

(b)

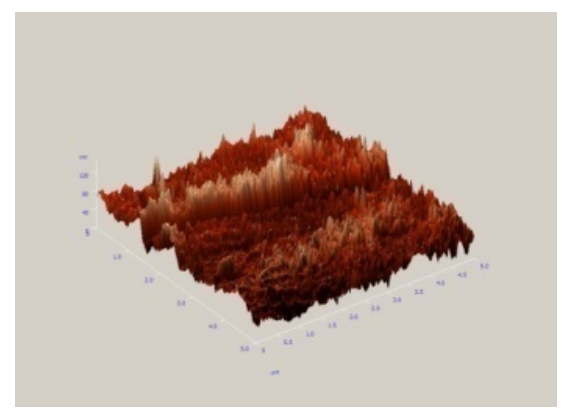

(d)

Figure 2: $\quad$ Surface topographies of (a) an uncoated stainless steel surface and surfaces coated with (b) an OTS film, (c) an OTS+anti10\% film, and (d) an OTS+anti50\% film. 


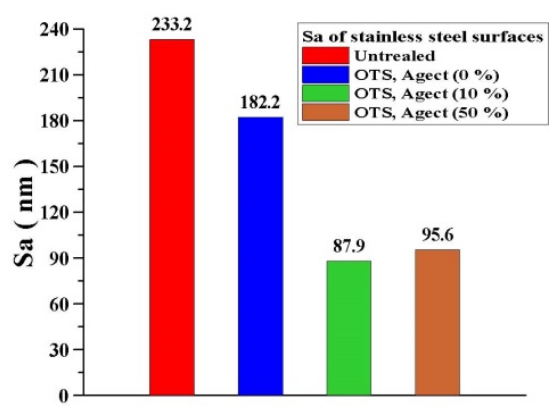

Figure 3: Surface roughnesses of the various hybrid self-assembled films formed on stainless steel substrates.

Table 2 shows that roughness parameters for the uncoated stainless steel surface and surfaces coated with various surface films. It also indicates that the peak-to-valley and ten point height values of surface films have the same trend as that of average surface roughness. However, it is interesting to note that the skewness value of uncoated stainless steel surface is minus. It shows that original stainless steel surface possess many small valleys and relative fewer peaks. The mechanism of OTS forms on the substrate is adsorption nucleation and then forming islands. The skewness values of surface with self-assembled films of OTS, OTS + anti $10 \%$, and OTS + anti $50 \%$ is $0.2,0.34,0.60$. It shows that the concentration of antimicrobial agent enhance the islands effect of surface film formation during the process.

Table 2: Roughness parameters for the various surfaces.

\begin{tabular}{|l|l|l|l|l|}
\hline & Uncoated & OTS & OTS+10\% & OTS+50\% \\
\hline Average roughness, $S_{\mathrm{a}}(\mathrm{nm})$ & 233.2 & 182.0 & 87.9 & 95.6 \\
\hline Peak-to-valley, $S_{y}(\mathrm{~nm})$ & 1358 & 1094 & 530 & 546 \\
\hline Ten point height, $S_{\mathrm{z}}(\mathrm{nm})$ & 676 & 546 & 254 & 272 \\
\hline Surface skewness, $S_{\text {sk }}(\mathrm{nm})$ & -0.90 & 0.20 & 0.34 & 0.60 \\
\hline
\end{tabular}

Figures 4-6 show the contact angles of the various hybrid self-assembled films formed for different soaking temperatures; the soaking time was $24 \mathrm{~h}$ and the concentration of the self-assembling agent was $10 \mathrm{mM}$. At $60^{\circ} \mathrm{C}$, the three surface films exhibited the same contact angle (as shown in Fig. 4). Furthermore, the contact angle was almost similar to that of the uncoated stainless surface $\left(96^{\circ}\right)$. This indicates that the films self-assembled at $60^{\circ} \mathrm{C}$ had no effect on the hydrophobicity of the steel substrates. However, when the soaking temperature was increased to $70^{\circ} \mathrm{C}$, the contact angle for all the surface films decreased, reducing to $55^{\circ}$ for the OTS film, $77^{\circ}$ for the OTS+anti $10 \%$ film, and $79^{\circ}$ for the OTS + anti50\% film (as shown in Fig. 5). Figure 6 shows the contact angles of the three surface films formed at $80^{\circ} \mathrm{C}$. It can be seen that the contact angles of all the films were lower than that of the uncoated substrate. From Figs 4-6, it 
can be concluded that, for the self-assembled film of pure OTS, the contact angle decreased as the soaking temperature was increased. However, in the case of the hybrid self-assembled films, this trend was not observed.

Figures 7 show contact angles of hybrid self-assembled films formed for the various soaking times at soaking temperature of $60^{\circ} \mathrm{C}$ and drying temperature of

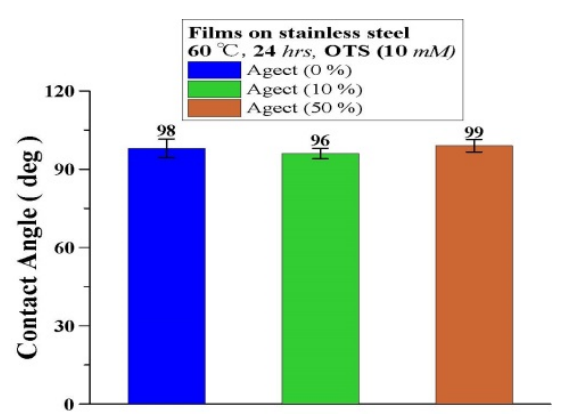

Figure 4: Contact angles of the various hybrid selfassembled films formed for a soaking temperature of $60^{\circ} \mathrm{C}$, drying temperature of $35^{\circ} \mathrm{C}$, and soaking time of $24 \mathrm{~h}$.

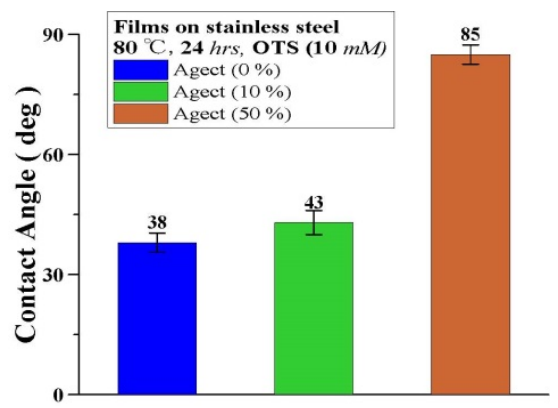

Figure 6: Contact angles of the various hybrid selfassembled films formed for a soaking temperature of $80^{\circ} \mathrm{C}$, drying temperature of $35^{\circ} \mathrm{C}$, and soaking time of $24 \mathrm{~h}$.

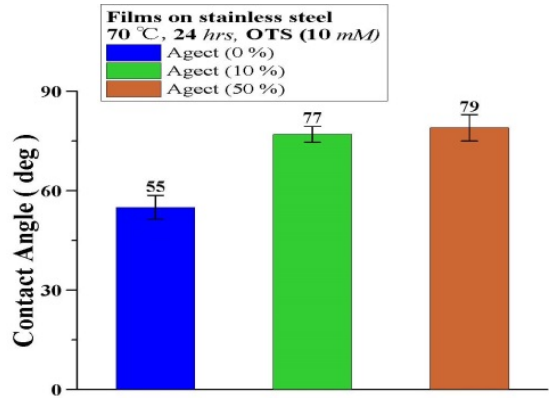

Figure 5: Contact angles of the various hybrid selfassembled films formed for a soaking temperature of $70^{\circ} \mathrm{C}$, drying temperature of $35^{\circ} \mathrm{C}$, and soaking time of $24 \mathrm{~h}$.

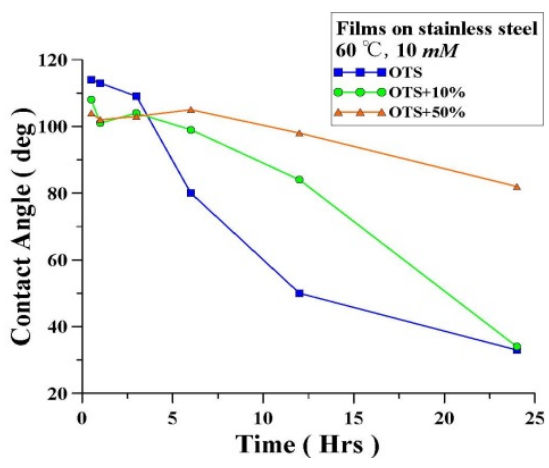

Figure 7: Contact angles of the various soaking times and hybrid self-assembled films formed for a soaking temperature of $60^{\circ} \mathrm{C}$, and drying temperature of $35^{\circ} \mathrm{C}$. 
$35^{\circ} \mathrm{C}$. The contact angle of pure OTS film decreases as increasing soaking time. The contact angle of OTS+anti10\% film decreases and then increase at soaking time of $3.0 \mathrm{~h}$ and then decrease as increasing soaking time. The variation trend of contact angle between OTS + anti $10 \%$ and OTS + anti50\% film is similar. However, the soaking time of the largest contact angle at OTS+anti50\% film is $6.0 \mathrm{~h}$. In conclusions, there are too many factors can affect the largest contact angle of the various films in our experiments. In order to obtain the largest contact of the various films, the Taguchi method was used in our work.

The optimisation of the synthesis parameters using the Taguchi method led to the following values: soaking temperature of $70^{\circ} \mathrm{C}$, drying temperature of $55^{\circ} \mathrm{C}$, soaking time of $0.5 \mathrm{~h}$, concentration of self-assembling drug of $20 \mathrm{mM}$, and concentration of antimicrobial agent of $10 \%$. We found that the contact angle of the uncoated substrate and that of the substrate coated with the hybrid film formed under optimal conditions were $96^{\circ}$ and $116^{\circ}$, respectively (as shown in Fig. 8). Thus, the contact angle of the substrate covered with the optimised hybrid film was $21 \%$ higher than of the uncoated substrate.

We also tested the antibacterial properties of the optimised hybrid film. This was done using the JIS Z 2801 test, which involves the use of $S$. aureus bacteria. The different self-assembled films were inoculated with the bacteria. Then, after $24 \mathrm{~h}$, the numbers of bacteria present were determined (as shown in Fig. 9). The yellow dots represent new bacteria. The surface on the left is completely covered with bacteria. The number of bacteria on the uncoated substrate was $2.83 \mathrm{E}+005$ $\mathrm{CFU} / \mathrm{cm}^{2}$; this decreased to $0.63 \mathrm{CFU} / \mathrm{cm}^{2}$ for the hybrid film (as shown in Fig. 10). Thus, it was confirmed that the antimicrobial agent in the selfassembled film exhibited antibacterial functionality.

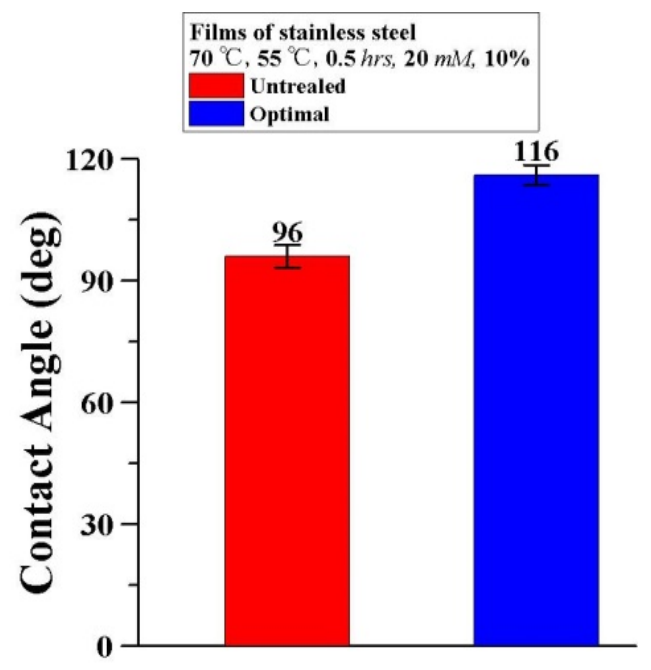

Figure 8: The contact angles of optimal surface film on stainless steel substrate in the Taguchi method. 


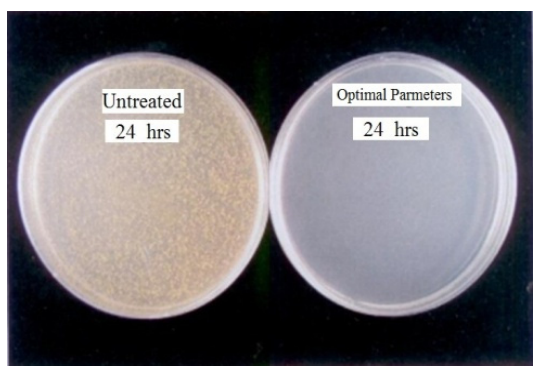

Figure 9: Photographs showing the results of the antibacterial test after $24 \mathrm{~h}$ (yellow dots represent bacteria).

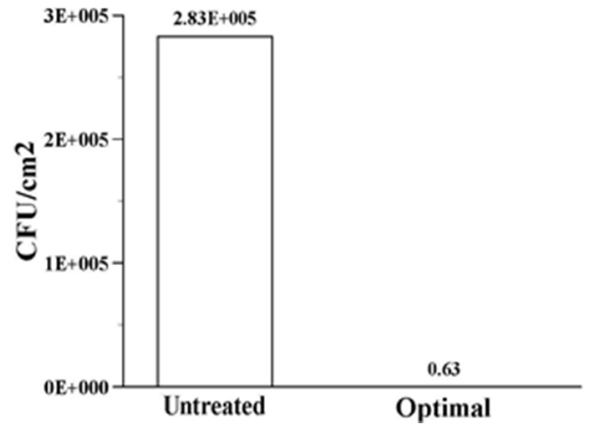

Figure 10: Antibacterial functionality of a hybrid film selfassembled under optimal conditions, determined using the Taguchi method.

\section{Conclusions}

We characterised the antibacterial and antifouling properties of self-assembled molecular films formed on stainless steel substrates by controlling five process parameters, which were optimised using the Taguchi method and found to be the following: soaking temperature of $70^{\circ} \mathrm{C}$, drying temperature of $55^{\circ} \mathrm{C}$, soaking time of $0.5 \mathrm{~h}$, concentration of self-assembling agent of $20 \mathrm{mM}$, and concentration of antimicrobial agent of $10 \%$. The contact angle of the film formed under these conditions was $116^{\circ}$. Further, during the JIS Z 2801 test, a thus-synthesised hybrid film exhibited a decrease in the number of $S$. aureus bacteria, which reduced to $0.63 \mathrm{CFU} / \mathrm{cm}^{2}$. Thus, the antibacterial activity value of the film was 5.7, which is higher than the standard value of 2.0 for the materials used for industrial and biomedical applications.

\section{Acknowledgement}

The authors gratefully acknowledge financial support provided by the Ministry of Science and Technology of Taiwan under Contract No. NSC 103-2221-E-150009-MY2.

\section{References}

[1] N. Kumar, C. Maldarelli, C. Steiner, A. Couzis, 2001, "Formation of Nanometer Domains of One Chemical Functionality in a Continuous Matrix of a Second Chemical Functionality by Sequential Adsorption of Silane Self-Assembles Monolayers", Langmuir, Vol. 17, pp. 7789-7797. 
[2] C. M. Knobler, D. K. Schwartz, 1999, "Langmuir and Self-Assemble Monolayers", Current Opinion in Colloid \& Interface Science, Vol. 4, pp. 46-51.

[3] A. Tillman, A. Ulman, J. S. Schildkraut, 1988, "Incorporation of Phenoxy Groups in Self-Assembled Monolayers of Trichlorosilane Derivatives. Effects on Film Thickness, Wettability, and Molecular Orientation", Journal of the American Chemical Society, Vol. 110, pp. 6136-6144.

[4] P. Thebault, E. T. de Givenchy, R. Levy, Y. Vandenberghe, F. Guittard, S. Geribaldi, 2008, "Preparation and Antimicrobial Behaviour of Quaternary Ammonium Thiol Derivatives able to be Grafted on Metal Surfaces," European Journal of Medicinal Chemistry, Vol. 44, pp. 717-724.

[5] P. Thebault, E. T. de Givenchy, R. Levy, Y. Vandenberghe, F. Guittard, S. Geribaldi, 2009, "Contact-active Microbicidal Gold Surfaces using Immobilisation of Quaternary Ammonium Thiol Derivatives," European Journal of Medicinal Chemistry, Vol. 44, pp. 4227-4234. 